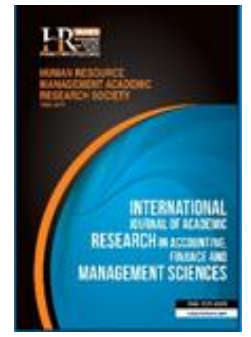

International Journal of Academic Research in Accounting, Finance and Management Sciences

Vol. 9, No.1, January 2019, pp. 123-135

E-ISSN: 2225-8329, P-ISSN: 2308-0337

(C) 2018 HRMARS

www.hrmars.com

To cite this article: Alhilfi, M. (2019). Role of using the Relative Strength Index in Making Speculation Decision in Stock Applied Research in the Iraq Stock Exchange, International Journal of Academic Research in Accounting, Finance and Management Sciences 9 (1): 123-135.

\title{
Role of using the Relative Strength Index in Making Speculation Decision in Stock Applied Research in the Iraq Stock Exchange
}

\begin{abstract}
Murtadha Alhilfi
Southern Technical University, E-mails: Murtadha.ameen@stu.edu.iq, Murtadha.ameen@gmail.com

Abstract

The Investment in the Stock Exchange is a fundamental aspect in modern economics, especially the investment in the shares of companies, it became attracting a lot of Investors and speculators with different objectives according to possibilities and nature each one of them, but these participants in the Stock Exchange hesitate about find the better Investment opportunity for them. They have Fears of bad decision Investment that don't give a high return with the lowest risk. This makes the Investors and speculators need to use an Indicator that helps them in making a rational speculation decision, And one of best indicators is Relative Strength Index RSI which Can determination the appropriate timing for speculating in the shares of companies depending on the historical data of prices stock. Given that the speculators in the Iraqi stock market are afraid to enter into speculation because of lack of finding the best tools that guide their decisions, and for this reason, this subject has been chosen. This study is aimed to know the role of using the Relative Strength Index in making the best decision to speculate on shares listed in the Iraqi Stock Exchange and on this basis this problem the research has the main question: ((How can RSI be used to make an optimal decision to speculate on stocks?). It concluded in this study that the use of Relative Strength Index had a fundamental and effective role in rationalizing the speculation decisions in the shares of the Bank of Baghdad which listed in the Iraq Stock Exchange, Where assist on determination of the right timing for investment through forecasting shares prices upwards and downwards, The Speculator Purchase at forecasting the price will upward and selling at forecasting the price will downward.

Key words

Market Papers Finance, Investment, Speculation, the decision Investment, Stock, Relative Strength Index

Received: 30 Apr $2019 \quad$ (c) The Authors 2019

Revised: 15 May 2019 Published by Human Resource Management Academic Research Society (www.hrmars.com)

Accepted: 25 May 2019 This article is published under the Creative Commons Attribution (CC BY 4.0) license. Anyone may Published Online: 28 May 2019

This article is published under the Creative Commons Attribution (CC BY 4.0 ) license. Anyone may
reproduce, distribute, translate and create derivative works of this article (for both commercial and non-commercial purposes), subject to full attribution to the original publication and authors. The full terms of this license may be seen at: http://creativecommons.org/licences/by/4.0/legalcode
\end{abstract}

\section{Introduction}

The first tool needed for developing the economy of any country is the provision of funds which required by the companies in order to expand its activities. hence, the companies are looking for different sources of funding to fulfill their financial needs, and because the traditional sources of funding like investment in bonds are costly sources which required paying interests, also it generates a fixed returns, for that, the owners of companies and the investors need for investing tools to help them to reduce the interests paid to lenders, and at the same time generates growing income for them like investment in stocks.

Since the stock Exchange is including a high level of risk. Hence, the speculators became looking for the best tools which enable them to reduce the risks of investing in they the stocks of companies. And this 
can be done by observing the prices movements for a particular share and show it in charts "this is what called as the technical analysis" then use this data to predict for the future price of stocks by using technical indicators.

The Relative Strength Index (RSI) is one of the most used indicators in technical analysis, it is an instrument helps the users of technical analysis in understanding and reading technical charts, and then predicts the future trends of prices in the financial Exchanges and measure the range of price movements.

This research aims to know the effectiveness and role of technical analysis by using the RSI to make speculation decision to in-stock Exchange at the right time.

\subsection{Research problem}

The decision of speculation in stock Exchange, especially the speculation in stocks of companies, is one of the most difficult decisions because speculation in the Stock Exchange is too risky. This caused by many psychological factors which affect the decisions in the short term and restricting those who want to speculate the Stock Exchange. And because there are many companies offering its stock for investment, it becomes necessary to select the best-suited company for speculation among them and then determine the right time for speculation. And here it is necessary to use the tools of the technical analysis to select the best-suited company for and determine the right time for speculation. And because the technical analysis includes many indicators, this make the speculator confuse about choosing the best one make him able to rationalize his decision. From here we see the problem of study and so on the study has this question ((How to use the RSI in making the right speculation decision in stocks).

\subsection{Importance of research}

The speculation in the Stock Exchange is too risky; therefore, the speculators live in an atmosphere of uncertainty about what will the stocks prices in the future. The speculator buys stocks when its prices are decreasing and then sell them when its prices are increasing, in case the share price fell today, it may fall further tomorrow or it may begin rise. Hence, the Speculators are confusing about the ideal timing to buy and sell the stocks, and this makes them need to use a financial analysis method to make the best speculation decision. The importance of this research is stated in showing up the role of technical analysis by using the RSI in supporting the speculators to making the best speculation decisions in the Iraq Stock Exchange.

\subsection{Research Objectives}

The research aims to achieve the following objectives:

- Showing up the role of technical analysis by using the RSI to make the best speculations decisions

- Making the best speculation decisions by predicting future prices movements.

- Giving suggestions to contribute to developing the process of making speculations decisions in stocks.

\subsection{Research Hypothesis}

In view of the problem and objectives of the research, I had formulated the main hypothesis "The technical Analysis by using RSI contribute in making the best speculation decision in stock", and from it, two sub-hypotheses derived as follows:

- The technical analysis observes the historical price movements of stock by representing it on a chart, and this historical trend is helping in predicting the future price for the same stock.

- Using the RSI has a role in making the best speculation decision of selling and buying stock in the Iraqi Stock Exchange at the right time.

\subsection{Research Limits}

- Locative limits: The Bank of Baghdad which listed in the Iraqi Stock Exchange.

- Time limits: 2016 (Using the financial statement's data for the year 2016). 


\subsection{Research Methodology}

The research used two approaches, they are:-

- The Inductive Approach: The research methodology was adopted the Inductive approach in explaining and studying the general concepts and theoretical foundations related to technical analysis depending on the most important sources and different scientific references.

- The Analytical Approach: Utilize the technical analysis by using the RSI as an analytical approach to predict the future stocks prices in the Iraqi Stock Exchange.

\subsection{Research Scheme}

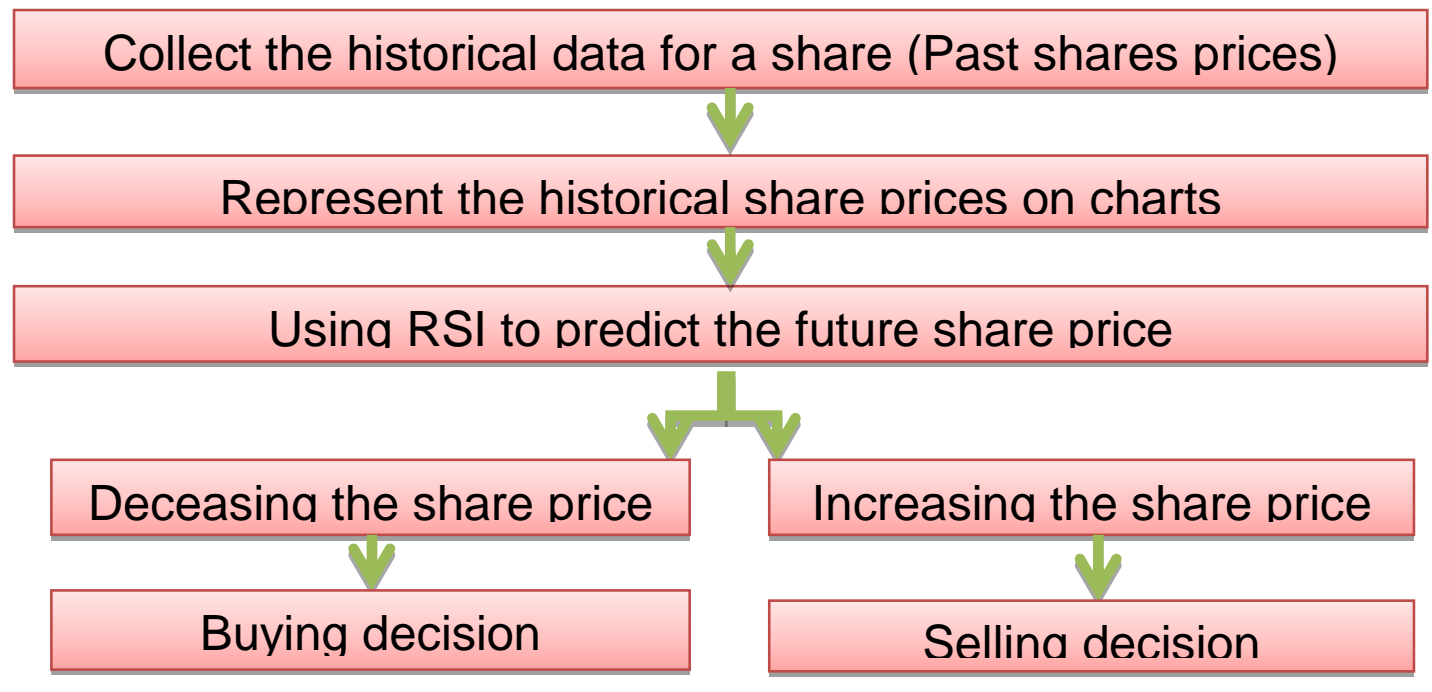

Figure 1. Prepared by the researcher

\subsection{Previous Studies}

This study aimed to test the functioning of the RSI in its classic form, on a set of data and to reconfigure the index by also taking account of the trading volume in its calculation formula. After adjusting the indicator with the trading volume, finally, it compares $d$ the obtained results by applying the classic form of the indicator with those obtained by using the adjusted form. The study concludes that the revisited RSI do not indicate the return of a trend but the continuation of its direction (Taran-Morosan, 2011). This study is aimed at carrying out technical analysis of the stocks of selected Indian companies and to assist investment decisions in Indian Stock Exchange where it has concluded, the technical analysis is utmost importance to predict the trend of short and medium-term price movement and help the investors to select the right plan and decisions to invest in the remunerative stocks (Boobalan, 2014).

This study was conducted in the Riyadh Stock Exchange and the Abu Dhabi Stock Exchange. The study aimed to show the technical analysis steps, hypotheses, models, indicators, strengths, and weaknesses, as well as the technical indicators used in the technical analysis, the use of the Relative Strength Index to make the investment decision, the decision to buy and sell off stocks at a suitable time. The study concluded that using technical analysis and its indicators leads to the accuracy and credibility of investment decision making (Al-Shukriji, 2010). This study aimed to know the effect of technical analysis on resolution Investors inside Exchange Palestine. It has carried out on a number of Investors and activist people working in brokerage companies in Gaza city. The study concluded that the technical analysis clear and easy the use. And that Investors continuously observing the technical analysis charts to predict the market prices movement. It helps in determining the right time to enter the market and the right time to leave the market (Abu Hatif, 2011).

\subsection{Position of the current study of previous studies}


The previous studies present the technical analysis as a method for analyzing the stocks of companies and knowing which one of them is better for investment, while the current study tried to encourage investors for speculation in the stocks of the Iraqi Stock Exchange, through the studying of the role of technical analysis approach by using the RSI to predict the movements on share prices in the future, where the historical prices of stocks were used as inputs to the analysis This what distinguishes this study from the previous studies presented by the other researchers.

\section{Literature Review}

\subsection{Stock Exchange Concept}

The origin of the word Bursa is a name of a Belgium family called van der Borson Van der who was working in the banking business and whose hotel was in Bruges city was a place for the meeting of the local merchants in the fifteenth century. It became a symbol of the capital Exchange and Stock Exchange (Iraqi Stock Exchange website). Since entrepreneurs are always looking for the best alternatives available to fitful the financial needs of their projects, and since financing through bank borrowing is a classic method for financing, which entails the payment of interest and a specific period of repayment of the loan amount, this lead to needing for creating and establishing of stock Exchanges able to exploit the available resources and put them into projects with a view to achieving an adequate return. Bursa is designated as a Stock Exchange, it is a regular market, and therefore it is an independent entity governed by its regulations, instructions, and rules. It includes selling and buying the stocks and securities which registered and listed in the operations through licensed brokerage firms and supervised by the Board of Directors (Al Thunibat, 2009).

Accordingly, the Stock Exchange is a regular market through it the listed securities are traded under the rules and procedures determined by the Commission of the Exchange (Al Tamimi, 2010). Thus, it is clear that financial securities have a special Exchanges through which these instruments or securities are traded, and thus, it serves as the channel through which money flows from savers to investors and vice versa. The researcher sees that the Stock Exchange is a place where the sellers and buyers of securities are meeting and by that, the quantity of traded securities can be determined as well its price, on a specific time.

\subsection{Investment and Speculation Decisions in Stock}

The stock Exchange attracts many of investors and speculators as it fitful them different kinds of requirements and achieve them goals where many financial assets are traded like stocks and bonds "buy them when its prices fell down and sell them when its prices rise up" in order to take advantage from the price difference, and this is known as speculation in stock (short-term investment). Investors investigate many factors when deciding to invest, but as stated by many of financial management experts, efficiency and risk are two significant factors that influence investment decision (Moghaddam, 2015). It is clear that there is a psychological factor lead to price fluctuation of stock in the short term for one day or more like the fear or the greed of the investors and speculators, and so the stock prices get out of the rationality. Here, the rational investor takes advantage of this opportunity and buy the stock when its prices fell below its fair value (Al Thunibat, 2009).

A question arises, is the speculation in stocks investment? Or, is there a relative difference between the investment and speculation in stock? In fact, the difference between them is the period of holding the stock and the amount of risk. The investment is for a longer period, long-term investment. If the stock price fell down, here the investor in the case he refuses the idea of selling his stock at a price below the purchase price and decides to wait until the price rises up again, this is a long process or a long-term investment (investment in stocks). In another hand, if he accepts to sell his stock in accordance with the Exchange prices whatever it high or low. Here, this is speculation because he does not hold the stock for a long period of time and he accepts a certain risk possibility (Al-Muhailmi, 2006). The speculator is someone who able to predict the future after making the required analysis and he accepts some risk possibility in order to make profits, so he must have some of the qualities that distinguish him from others, including the ability to deal with the possibilities because the Exchange is not determinism (Al Thunibat, 2009). 


\subsection{The Technical Analysis}

\subsubsection{The concept of Technical Analysis}

That Successful Participation in the stock Exchange requires a good level of knowledge about the technical analysis, and should we put in consideration that all decisions in stock Exchanges Of all kinds are depending on the forecasting, Whether the participant in Exchange is a short-term trader (speculator) or a long-term trader (investor). Hence, the process of forecasting the prices in stock Exchange is the first step in making the investment decision process (Murphy, 2000).

The technical analysis primarily aim to identify the trends of prices and reveal any indication could tell us about the possibility of prices change as soon as possible so that it can be used for making decisions of buying or selling the stock at the appropriate times in order to reduce risks and maximize profits (AlMuhailmi, 2006). It is included different strategies and techniques that attempt to estimating future prices with the study of the previous price and so on in technical analysis the previous movement of the prices of stock and demand/ supply forces influencing stock price is highly important.

The technical analysis is the process of studying past prices and the volume of stock trading, draw it with a chart, then predict the future trends of prices which advise about the appropriate time to buy stock (Exchange access), and advise about the appropriate time to sell them (exit the Exchange), all that can be done by using a certain models that have clear indicators in the investment making decision process.

\subsubsection{The different between the technical analysis and the fundamental analysis}

The technical analysis is a tool of forecasting, it focuses on studying the movement of stocks prices and work to predict the trend of prices by observing its past prices. But the technical analysis does not study the reasons behind these movements. Whereas in the fundamental analysis, it examines the fundamentals at the level of macroeconomic, at the industry level of the sector operated by the company, or at the level of the company itself (Al Thunibat, 2009).

While economists and fundamental analysts are studying the of price movements, they are always looking for the reasons behind the prices movements in a certain trend, The technical analysts do not give attention to the reasons for the movements, their attention is mainly focused on the number of price movements, the trading volume and for how long it continued and most importantly, the impact of these movements on the general position of the Stock Exchange. The technical analyst focuses on knowing the trends of prices and studying the behavioral patterns in its various forms which are often repeated, that exactly what helps the investor in predicting the movements of prices in the future (Al-Muhailmi, 2006).

The technical analysis based on studying the prices movements in the Stock Exchange while the fundamental analysis based on knowing the reasons which lead to prices movements upward or downward. The technical analysis is very useful in predicting prices movements the prices, it can use combined with or without the fundamental input. Anyway, it remains Just a step in the process making the investment decision (Murphy, 2000).

Hence, the fundamental analyst provides the investor with a list of the reasons and factors affecting the movement of prices, while the technical analyst provides the investor with trends of prices movements and volume of trading of stock. That means, the first takes the reasons and the second takes the results in the planning for its work strategy in the Stock Exchange (Shawashra, 2008).

\subsubsection{The tools of the technical Analysis}

The tools of technical analysis for stocks of companies can be applied on the whole Stock Exchange or on certain securities in accordance with the purpose of analysis if the purpose of it is to know the general trend of the Stock Exchange; it has to be applied on a whole Stock Exchange. While, if the purpose is to give a signal to the investor about the appropriate time for buying or selling of securities, then it has to be applied on the individual securities as in the case of this research.

2.3.3.1. The Relative Strength Index Indicator 
According to FX-ARABIA, the leading sit for teaching stock trading in the Arab world, the RSI is an indicator that is based on comparing the upward trends with the downward trends for a specified period of time and turns the results into numbers ranging from zero to hundred. It is a very important indicator of speculators, its values depends on calculating the average closing prices which rose, and divide it on the average closing prices which drop, by using an equation for a certain period, it depends on whom calculating its value, normally takes 14 days for the speculators, and a longer period for the investors. When the value of the RSI is less than 30, it indicates to enter the Stock Exchange by buying offered stocks, and when it from 31 up to 60 , it indicates to a cautious entry, while when its value is more than 61 , it indicates to leave the Stock Exchange by selling their stocks (Al Tamimi A. M., 2005).

The RSI is used to identify the overbought and the oversold, the overbought means that the Stock Exchange protracted prices are moving to the upside, the oversold means that the Stock Exchange protracted prices are moving to the downside. The discoverer of this indicator, Welles Wilder, used the $30^{\text {th }}$ and $70^{\text {th }}$ levels as overbought and oversold levels and felt that they corresponded to the price movement, as they are shown in the Figure (2). If the RSI falls down the $30^{\text {th }}$ level and then rises above it again, this is a strong signal that the buyers have returned to dominate the Stock Exchange and that is overbought, for that the price trend will continue rising up. While, If the RSI rose up the $70^{\text {th }}$ level and then flown again, this is a strong signal that the sellers have returned to dominate the Stock Exchange and that is oversold, for that the price trend will continue going down.

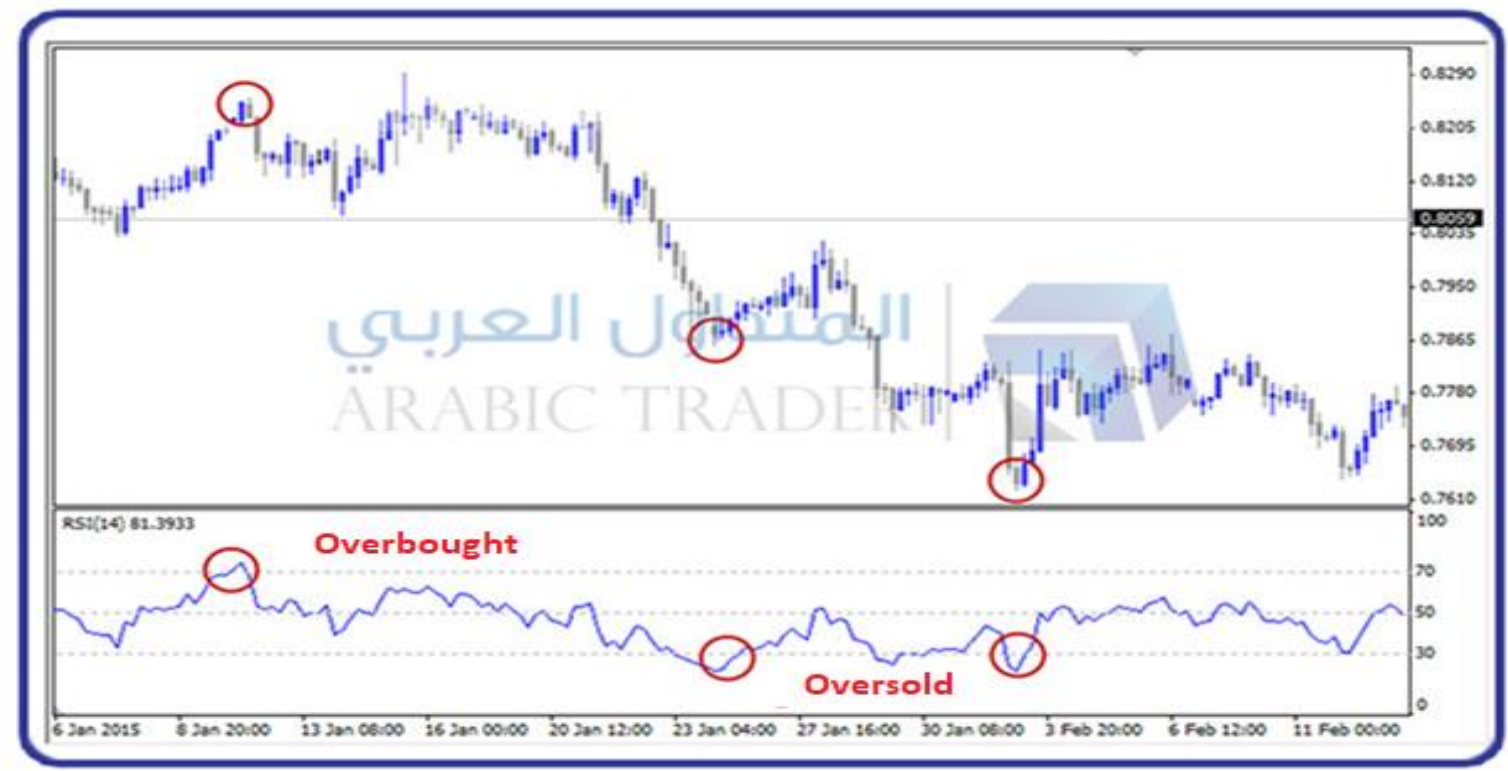

Figure 2. Arab Trader website

Calculation the RSI: - Relative Strength Index = 1 + Relative Strength/100-100

Relative Strength $=$ Average closing prices which rose/Average closing prices which drop

From the point of view of Welles, the uses of 14 days in this equation on the basis that it represents the half the lunar cycle or 28 days, but this not a standard, and you can determine any period of time depending on the range used the short or long term (Alpha \& Beta for money and economy website).

\subsubsection{Charts (Maps)}

Charts are using to identify the future trends of the Stock Exchange by examining the prices and volume of trading. It is also a tool which uses to determine the appropriate time for buying and selling the stocks (Al Tamimi, 2010). It is known that drawing the daily columns is the most common type of charts used for technical analysis. However, there are other types of charts used by the technical analysts according to their desire, such as the liner chart and drawing Japanese candles, etc. In this study, we used the liner chart because it is the simplest type by which a certain price chooses for a given period; normally the closing price is the price which represents as a price for that period (Abu Tarboush, 2010). 
In Figure 3, the vertical axis represents the price, and the horizontal axis represents the time period. This figure recorded the daily closing prices by putting a spot on its position on the chart, are then connected these spots one with others to make a line. This line reflects the movement trend of prices (AlMuhailmi, 2006).

\subsubsection{Levels of Support and resistance}

The levels Support and resistance are levels at which the trends of prices are expected to stop before it continues to move in the same direction or reverse from where it comes from, this happened because of the intensity of buying and selling transactions at these levels (Abu Tarboush, 2010). Figure 4 shows the levels of resistance and the levels of support as follows:

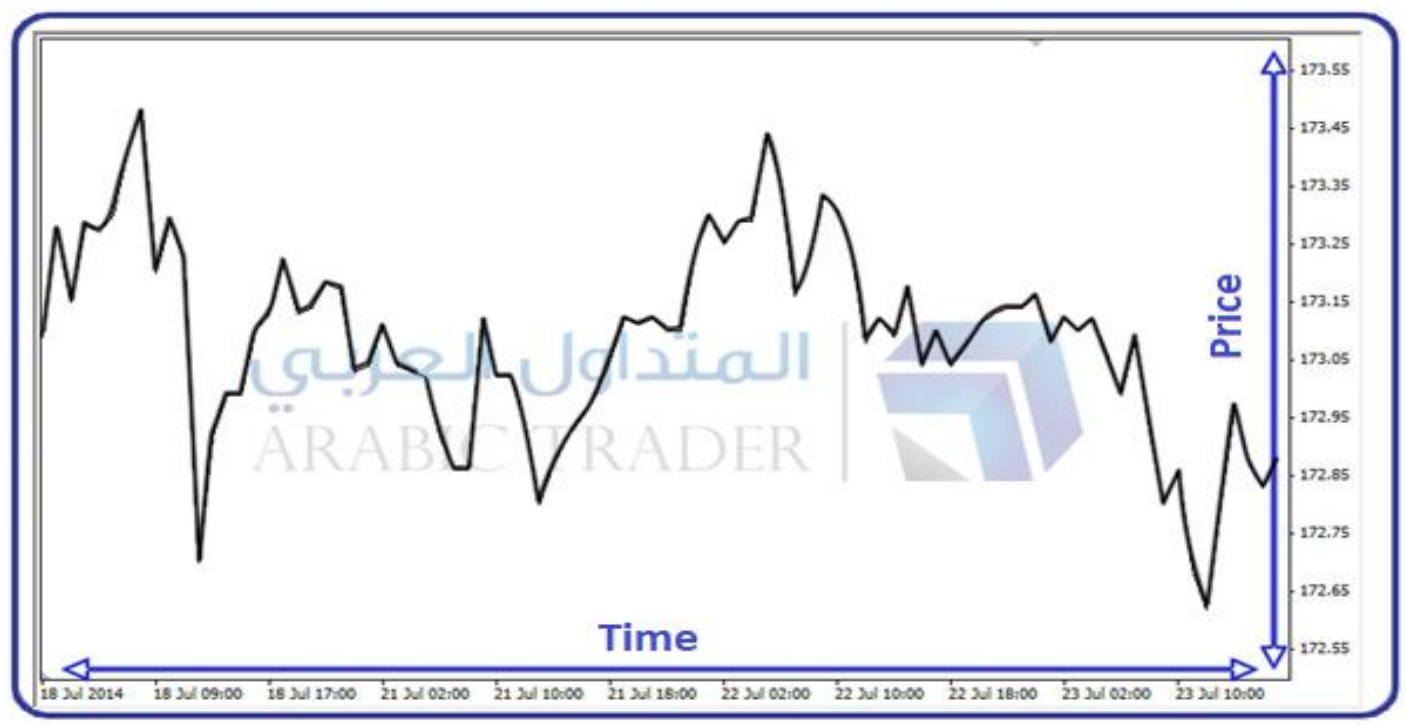

Figure 3. Arab Trader website

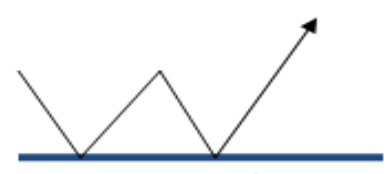

Resistance Level

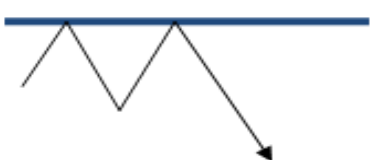

Support Level

Figure 4.

From figure (4) we find that when the trend of the price is going upwards, it has reversed back again downwards, this happens because of the existent of the resistance line. On the other hand, when the trend of the price is going downwards, it has reversed back again upwards, this happens because of the existent of the support line. The resistance line is drowning as a line connects all the highest spots the stocks prices have reached by the price to each other, it showed in the upper-level area on the chart. The high-level area of the chart which the price reach it again and again, and which on the Stock Exchange is not allowed to overcome represents a strong resistance, here many speculators decide to make sell decision at this level.

While the line of support is drowned as a line connects all the lowest spots to each other, it showed in the lower level area on the chart. The low-level area of the chart which the price reach it again and again, and which on the Stock Exchange is not allowed to overcome represents strong support, here many speculators decide to make buy decision at this level (Yalla Forex website).

\subsubsection{Breakout Patterns of Support and resistance}

The real breakout is the ability of price movement through the level of support or resistance and continues for a long period of time by implementing transactions more than the normal rate. The long 
periods of time and a large number of transactions make more traders dealing during this period that committed and defending this level of prices (breakout).

The price does not always reverse from where it comes from at the support and resistance levels, but it can exceed the levels of support and resistance, which is known as a breakout (Trendaat website).

If the level of resistance has broken, it means that the price will continue in the bullish trend for a long period. Hence, a stock buying decision has to be made because the price will rise up soon as shown in Figure 5. On the other hand, if the level of support has broken, it means that the price will continue in the bearish trend for a long period. Hence, a stock selling decision has to be made because the price will fall down as soon as shown in Figure 6.

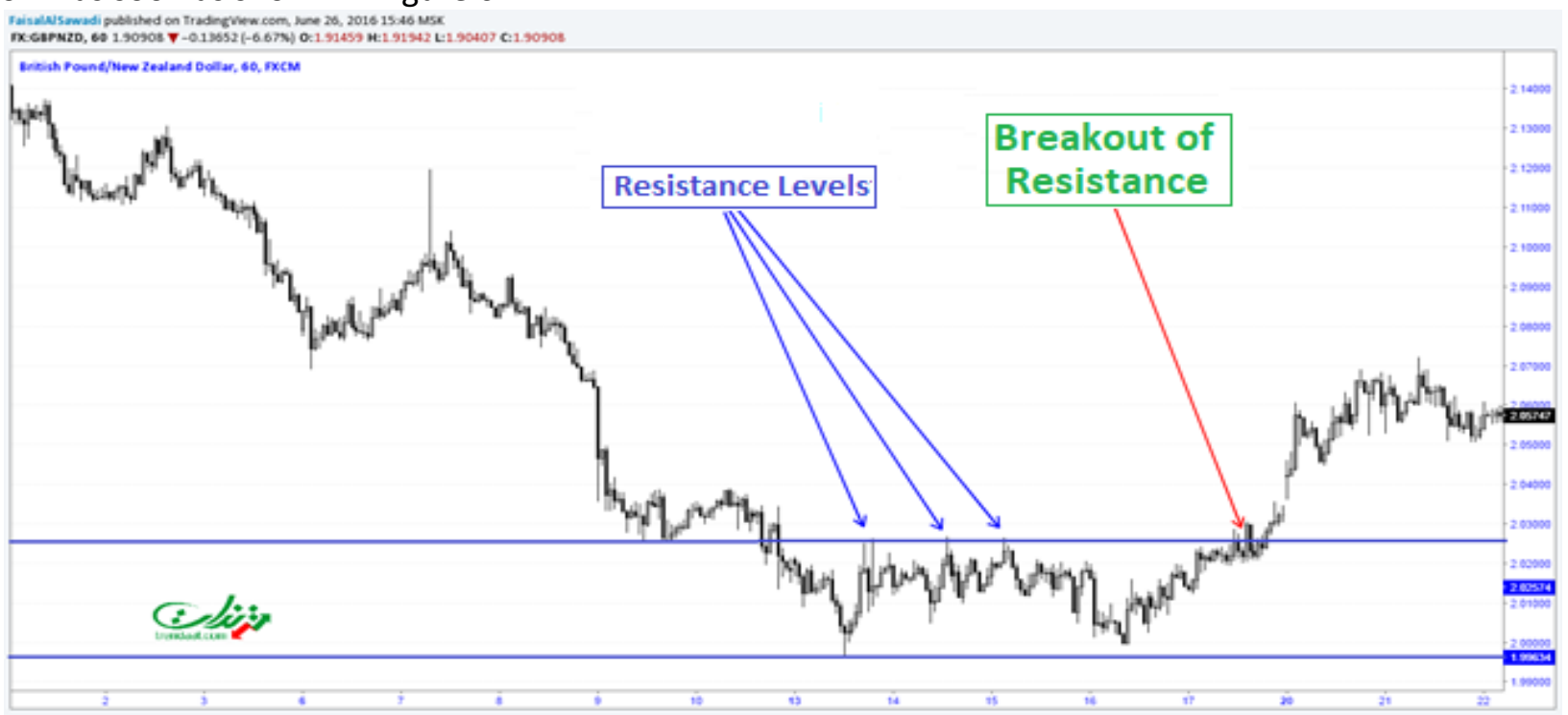

Figure 5.Trendaat website

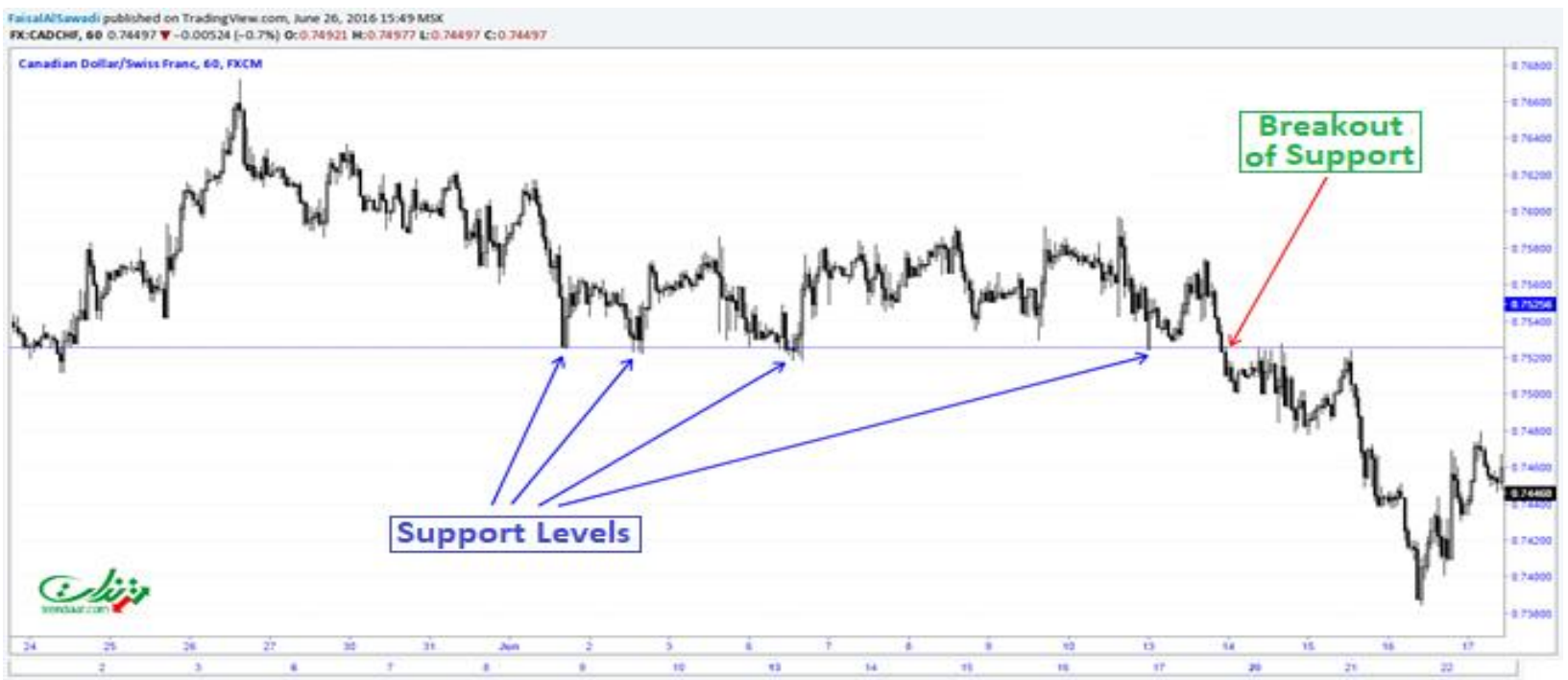

Figure 6. Trendaat website

\section{Research Methodology}

\subsection{Introduction}

In this research paper, the researcher will test the role of technical analysis by using the Relative Strength Index (RSI) In making the speculation decisions in stocks of a companies listed on the Iraq Stock Exchange, the RSI is uses to Show up to which extent technical analysis is useful to make the speculation decisions on stocks, and to which extent it helps to predict the trends of prices in the future, and then make the buying decision when the stock prices reach its lowest levels, or to make the selling decision when the stock prices reaches its highest levels . 


\subsection{About the Iraq Stock Exchange}

In 1992, Baghdad Stock Exchange was established under the law (24) for the year 1991 In the name of Baghdad Stock Exchange and in 2003 the name was replaced to Iraq Stock Exchange. Baghdad Stock Exchange was a government Stock Exchange, and it has listed about (113) company at that time includes private and joint companies. It has attracted in its last year annual trading rates exceeded 17 million dollars. This Stock Exchange was closed by the Board of Directors' decision on 19/3/2003. On April 18, 2004, the provisional law No. 74 was issued to establish two institutions in the capital sector; they are the Iraq Stock Exchange and the Iraqi Securities Commission (Iraqi Stock Exchange website).

According to Wikipedia, the free online encyclopedia, the Iraq Stock Exchange is Stock Exchange placed in Baghdad city, it was established in June 2004, and it operates under the supervision of Iraqi Securities Commission, Which is an Independent entity that developed alike to American Securities and Exchange Commission. It includes all companies listed on the Iraqi Stock Exchange including different sectors like banking, insurance, investment, industrial companies, hotels, tourism companies, agricultural companies, and telecommunications companies. The total number of listed companies until 12/2015 was (98).

\begin{tabular}{|c|c|c|c|c|c|}
\hline 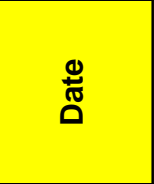 & 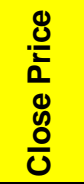 & 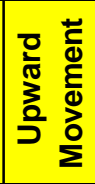 & 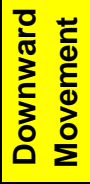 & $\infty$ & ळ \\
\hline & 1.12 & $\mathrm{~N} / \mathrm{A}$ & $\mathrm{V} / \mathrm{A}$ & & \\
\hline & 1.09 & .00 & 03 & & \\
\hline & .05 & & & & \\
\hline & .05 & 00 & 00 & & 481 \\
\hline & & & 00 & & \\
\hline & - & & & & \\
\hline & .02 & & & & \\
\hline & .02 & & .00 & & $\# \mathrm{~N} / \mathrm{A}$ \\
\hline & .01 & & 01 & $\mathrm{~N} / \mathrm{A}$ & $\mathrm{N} / \mathrm{A}$ \\
\hline & 01 & & 00 & & \\
\hline & 05 & & .00 & & $\# \mathrm{~N} / \mathrm{A}$ \\
\hline & 04 & & 01 & N/A & $\mathrm{N} / \mathrm{A}$ \\
\hline & 01 & & & & $\mathrm{~N} / \mathrm{A}$ \\
\hline & & & 01 & & $\# \mathrm{~N} / \mathrm{A}$ \\
\hline & 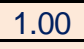 & & & & \\
\hline & 95 & & 5 & 22 & 3.18 \\
\hline & 96 & & 00 & 36 & 6.32 \\
\hline & 99 & & & & \\
\hline & .01 & & 00 & 71 & 1.67 \\
\hline & .03 & & & & 6.15 \\
\hline & 8 & & & & \\
\hline & 1 & & & & .17 \\
\hline & & & & & 8.33 \\
\hline & 0 & & 0 & & 8.33 \\
\hline & & & & & 50.00 \\
\hline & 40 & & & 22 & 5.00 \\
\hline & 104 & & 02 & 38 & 7.89 \\
\hline & & & & & 57.89 \\
\hline & & & & 22 & 55.00 \\
\hline & 1.02 & & 00 & 75 & 73.33 \\
\hline & & & & & 71.43 \\
\hline & & & & .15 & 63.64 \\
\hline & 1.00 & & 02 & 83 & 45.45 \\
\hline & & & & & 30.00 \\
\hline & 0.99 & & 0 & 29 & 22.22 \\
\hline & 0.98 & & 0.01 & 25 & 20.00 \\
\hline & 0.96 & & 02 & & 9.09 \\
\hline & 0.96 & & & .10 & 9.09 \\
\hline b-16 & 0.97 & & 0.00 & 20 & 16.67 \\
\hline & 0.97 & & 0.00 & & 9.09 \\
\hline & 0.98 & & & 0.25 & 20.00 \\
\hline $1-M$ & 0.95 & 0.00 & 0.03 & 0.20 & 16.67 \\
\hline
\end{tabular}


Table 1. Prepared by the researcher

\subsection{The role of technical analysis in making speculation decision in the stock of companies}

We have applied the technical Index "Relative strength index" on the stock of the company which used for this study, is based on the following limits:

- Sample Study: Bank of Baghdad.

- The study period: 2016 from Jan 01, 2016 until Dec 31, 2016.

- The chart used for drawing the prices trend is based on the liner chart.

The selection of a specific time frame is determined by the analyst himself according to the desired period of investment, and it is possible to use any kind of charts to express the same price data and it is up to the analyst to choose the chart he wants ( Abu Tarbush, 2010).

\subsection{Applying the Relative Strength Index on the of stocks of Bank of Baghdad}

\subsubsection{About the bank}

The bank of Baghdad has established on February 18, 1992, with a capital of 100,000,000 Iraqi Dinar. It has listed in the Iraq Stock Exchange on Jun 15, 2004. Its capital at listing was 5,280,000,000 Iraqi Dinar. Its current listed capital is 250,000,000,000 Iraqi dinar (on Jun 30, 2017) (Iraqi Stock Exchange website).

The figure (7) summarizes the price movement of the stocks of Bank of Baghdad in 2016 which made by applying the Relative Strength Index (RSI). This figure will use to analyze the signals generated by applying RSI indicator on the stock prices. It has represented both of price curve and the RSI curve on different lines.

\subsubsection{Calculation the RSI for the Bank of Baghdad}

We have used Microsoft Excel In order to calculate and represent the Relative Strength Index where the historical closing stocks prices were obtained from the Bank of Baghdad data which published on the Iraq Stock Exchange website.

- Relative Strength Index (RSI)= $1+$ Relative Strength/100-100

- According to Welles, The Relative Strength (RS) = Average low session closing prices within 14 days/Average high session closing prices within 14 days.

Table (1) shows the calculation procedure for RSI values in Bank of Baghdad by using Microsoft Excel. All RSI values for the year 2016 have calculated by researcher, and as shown in Table 1, the researcher try to give show how he calculate the RSI values for Jan \& Feb in the Table 1. And on this basis all the values of RSI have been calculated up to the end of the year 2016, and finally the chart is represented by selecting the closing price and the RSI values and then going to the toolbar and from (Insert) we choose (Line Chart). Hence, the figure for both the share price and the RSI value is represented in different trends as shown in Figure 7. Note that share prices were obtained from the Iraqi Stock Exchange (Iraqi Stock Exchange website).

Figure 7. prepared by researcher

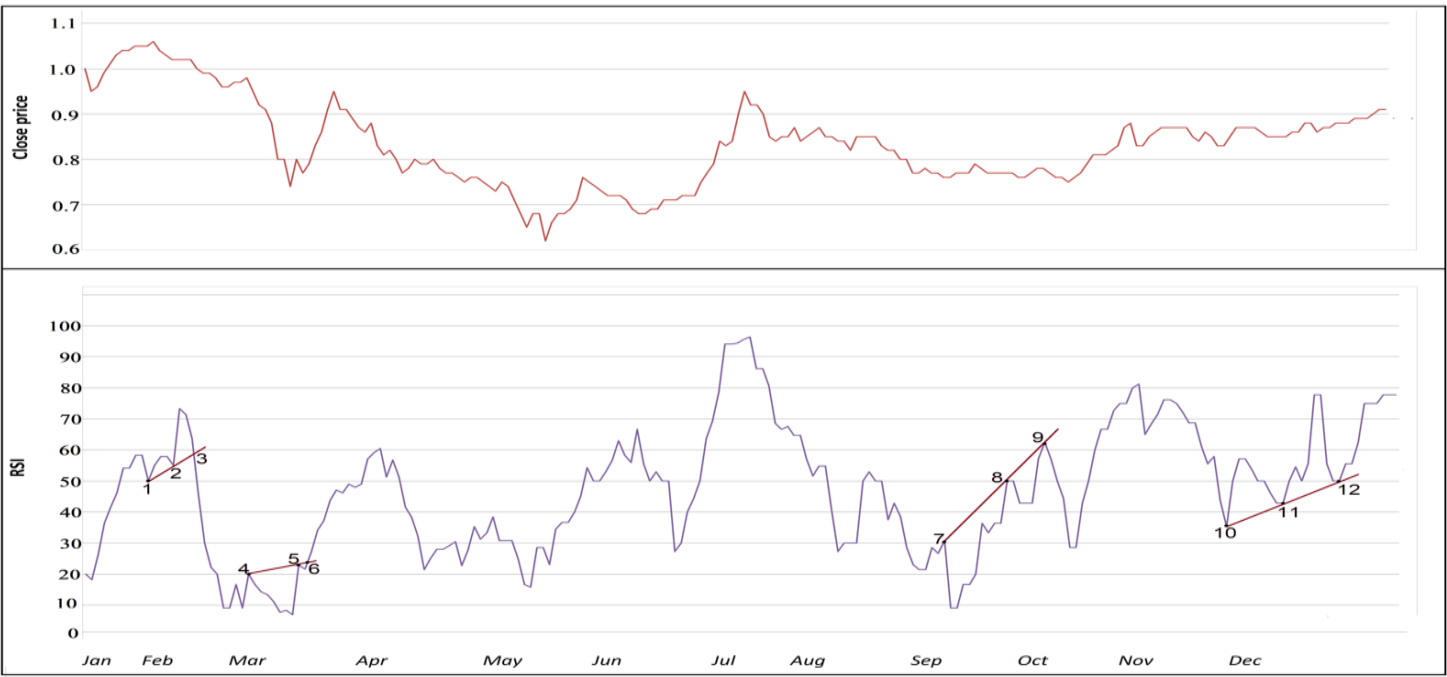




\subsubsection{RSI analysis for the Bank of Baghdad}

It is clear in the figure (7) that there are many selling and buying indicatives which generated due to the drawing of support and resistance lines. We will present some of these initiatives as fellow:-

First inductive: - A Support line was drawn from the swing low (1), where the RSI value is 50 on February 02, 2016, to the swing low (2), where the RSI value is 55 on February 11, 2016. This is a continuous line, and we have to wait until the price trend reaches the support line which we have drawn, this is a moment of anticipation, on which is better not to make any buying or selling decision for stock for the risk availability, and wait until the price trend excess or reverse the support line.

Since this line is a support line, connect the swing lows, it is likely to support the stock price "rise up the price trend", that means the price trend will reverse and rise up once it reaches this line. But in this case we see that the price trend has broken the support line (3) On February 16, 2016 when the share price was 1 Iraqi Dinar and continued to slipping down, here a selling indicative was generated where the support line has broken which means that there is a continues selling and buying transactions and there is a continuation of the price declining. Hence, the selling decision must be made and sell the stock before the price drops to its lowest levels. Later we notice that the price has indeed fallen to its lowest level on February 23, 2016, to 0.96 Iraqi Dinars.

Second indicative: - A resistance line has been drawn from the swing high (4). Where the RSI value is 20 on February 29, 2016, to the swing high (5), where the RSI value is 22.8 on March 10, 2016, this is a continuous line, and we have to wait until the price trend reaches the resistance line which we have drawn, and this is a moment of anticipation, on which is better not to make any buying or selling decision for stock for the risk availability, and wait until the price trend excess or reverse the resistance line.

Since this line is a resistance line connects the swing highs, it is likely to resist the stock price "slip down the price trend", that means that the price trend will reverse and slip down once it reaches this line. But in this case, we see that the price trend has broken the resistance line (6) On March 14, 2016, when the share price was 0.79 Iraqi Dinars and continued rising up. Here a buying inductive was generated we generated where the resistance line has broken which means that there is continues selling and buying transactions and there is a continuation of the price increase. Hence, the buying decision must be made and buy the stock before the price rises to its highest levels. Later we notice that the price has indeed risen up to its highest level on March 30, 2016, to 0.83 Iraqi Dinars.

Third Inductive: - A resistance line has been drawn from the swing high (7), where the RSI value was 30.7 on September 04, 2016, to the swing high (8), where the RSI value was 50 on September 25, 2016, this is a continuous line, and we have to wait until the price trend reaches the resistance line that we have drawn, and this is a moment of anticipation, on which is better not to make any buying or selling decision for stock for the risk availability, and wait until the price trend excess or reverse the resistance line.

Since this line Is a resistance line connects the swing highs, it is likely to resist stock prices, this means that the price trend will reverse and slip down once it reaches this line, and This is what actually happened, as the price trend has reversed down once it reaches the resistance line (9) on October 04, 2016, when the share price was 0.78 Iraqi Dinar, Here a selling indicative was generated as the price trend reversed which means that the price trend will continue falling down to its lowest levels. Here a selling decision must be made immediately, and we can then buy back the same stock when its prices fall. We noticed later that the trending price has indeed fallen to its lowest levels on October 10, 2016, to 0.75 Iraqi Dinars.

Fourth inductive : - The support line was drawn from the swing low (10), where the RSI value is 35.2 on November 15, 2016, 15/11/2016, to the swing low (11), where the RSI value 42.8 on November 29 , $2016,29 / 11 / 2016$, this is a continuous line and we have to wait until the price trend reaches the line that we have drawn, and this is a moment of anticipation on which is better not to make any buying or selling decision for stock for the risk availability, and wait until the price trend excess or reverse the support line.

Since this line is a support line connects swing lows, It is likely to support stock prices, this means that the price trend will reverse and rises up once it reaches the support line, and this what actually happened, as the price trend has reversed up once it reaches the resistance line (12) on December 13, 2016, when the share price was 0.0 .87 Iraqi Dinars, here a buying inductive was generated as the price trend reversed, which means that the price trend will continue rising up its highest levels. Here a buying decision must be made immediately, and we can then sell back the same stock when its prices rise. We 
noticed later that the trending price has indeed risen to its highest levels on December 25, 2016, to 0.91 Iraqi Dinars.

\subsubsection{Proof of the research hypothesis}

By analysis figure (7), it is clear that buying and selling decisions were made by using the RSI, which proves the validity of the research hypothesis which is (The technical Analysis by using RSI contribute in making the best speculation decision in stock). In figure (7), the historical price movements trend of the stock were observed by using the line chart, and this proof the first sub-hypothesis which is (The technical analysis observes the historical price movements of a stock by representing it on a chart, and this historical trend is helping in predicting the future price for the same stock). Also, in the figure (7) it's clear that the RSI is represented and used for the making the speculation decision in stock, and proof the second subhypothesis which is (Using the RSI has a role in making the best speculation decision of selling and buying stock in the Iraqi Stock Exchange at the right time).

\section{Conclusions and Recommendations}

\subsection{Conclusions}

- The using of The Relative Strength Index (RSI) reduces the risks of stock price fluctuation of the bank of Baghdad in the Iraq Stock Exchange.

- Using the RSI helped the speculators in the stocks of the bank of Baghdad in Iraq Stock Exchange in making buying and selling decisions by giving a proactive indicative.

- The Relative Strength Index (RSI) is an important and effective tool for the technical analysis of the stocks of the bank of Baghdad for its simplicity and the easy way for its calculation as is shown in the research paper.

- The Relative Strength Index (RSI) helps the speculators In the stocks of the bank of Baghdad in the Iraq Stock Exchange in proactive predicting of price trends and what prices will be in the future.

\subsection{Recommendations}

-We recommend implementing the RSI on the stocks any company in Iraq Stock Exchange before speculating in its shares for its role in making the right decision.

- Focus on the technical analysis by using the RSI by the speculators to make better speculation and use it to rationalize those decisions in the Iraq Stock Exchange.

- A high need to understand the rules of technical analysis by using its technical indicators by the speculators in the Iraq Stock Exchange to improve the decision-making process.

- A special necessity for doing more of studies in the field of technical analysis to help the speculators in the Iraq Stock Exchange for having bigger trading and transactions to make the market more active.

\section{References}

1. Al- Shawashra, F. M. (2008). Investment in the securities of Stock Exchange, Dar Wael for Publishing, First Edition.

2. Abu Hatif, N. K. (2011). The Effect of Technical Analysis on the Investors Decision In the Palestine Stock Exchange, Master's thesis submitted to the Department of Accounting and Finance, Faculty of Commerce, Islamic University - Gaza.

3. Abu Tarboush, R. M. (2010). Fraud and the International Stock Exchange, First Edition. Amman: Dar Safa For Printing, Publishing \& Distribution.

4. Al- Muhailmi, A. M. (2006). Manaeging the sucsess in stock exchane. Technical Analysis for Stock Exchange, Fifth edition. Private.

5. Al Shukriji, B. T.-D. (2010). Role of the technical analysis in making an investment decision in securities, an analytical study in a sample of Stock Exchanges in the Gulf Countries. Tikrit, Journal of Administrative and Economic Sciences/Volume - 6/Issue - 17. 
6. Al Tamimi, A. F. (2010). The Financial markets, regulatory framework and evaluation tools,. Dar Al Yazouri for Publishing and Distribution, Arabic edition.

7. Al Tamimi, A. M. (2005). Technical indicators, Part One. Collected and prepared by Al Tamimi, Abu Moaz, www.sall.com.

8. Al Thunibat, Z. F. (2009). How to trade In stocks, Dar Knoz Al Marifaa of publishing and distribution, first edition.

9. Al-Latif, N. K. (2011). The impact of technical analysis on the decision of investors in the Palestine Stock Exchange. Gaza: Master Thesis Introduction to Accounting and Finance Department, Faculty of Commerce, Islamic University, Gaza.

10. Alnoor A., E. B. (2019). Reverse Logistics on Sustainaable Manufacturing. International Journal of Academic Research in Accounting, Finance and Management Sciences.

11. Al-Shukriji, B. T. (2010). Role of the technical analysis in making an investment decision in securities. Tikret Journal of Administrative and Economic Sciences, Volume 6, Issue 17.

12. Boobalan, C. (2014). Technical Analysis in Selected Stocks of Indian Companies. International Journal of Business and Administration Research Review, Vol.2, Issue.4.

13. C.Boobalan. (2014). Technical Analysis in Selected Stocks of Indian Companies. International Journal of Business and Administration Research Review, Vol.2, Issue.4.

14. Moghaddam, A. G. (2015). Abolfazl Ghadiri Moghaddam \& others, The Relationship between EPS and CFO with Return on Shares in Companies Listed in Tehran Stock Exchange, Vol. 5, No. 4, 2015. International Journal of Academic Research in Business and Social Sciences.

15. Murphy, J. J. (2000). Charting made easy. Printed in the United States of America: Published by Marketplace Books ISBN 1-883272-59-9.

16. Taran-Morosan, A. (2011). The Relative Strength Index Revisited, African Journal Of Business Management. International Journal of Academic Research in Business and Social Sciences, pp. 5855-5862. 